\title{
Pattern of recurrence and prognostic factors in patients with $p$ T1-3 No esophageal squamous cell carcinoma after surgery: analysis of a single center experience
}

\author{
Gang Lin ${ }^{*}$ (D), Haibo Liu and Jian Li
}

\begin{abstract}
Background: The aims of this study were to determine the recurrence rate and the prognostic factors for recurrence-free survival (RFS) in esophageal squamous cell carcinoma (ESCC) patients without lymph node metastasis (LNM).

Methods: Between January 2011 and June 2017, 101 patients with ESCC were treated and pathologically confirmed to be lymph node negative. The clinicopathological parameters were evaluated to identify the prognostic factors for RFS using Cox proportional hazards models.

Results: Nineteen out of 101 patients (18.8\%) developed recurrence, and the median RFS was 41 months. The most common pattern of relapse was local recurrence $(n=11 ; 57.9 \%)$, followed by distant recurrence $(n=7 ; 36.8 \%)$; one patient developed local and distant recurrence simultaneously. The results of multivariate analysis showed that the independent prognostic factors for decreased RFS in node-negative patients were a tumor located in the upper chest (odds ratio [OR], $0.767 ; 95 \%$ confidence intervals $(C \mathrm{Cl}), 1.523-14.916, P=0.007$ ), the presence of lymphovascular invasion $(\mathrm{OR}, 3.534 ; 95 \% \mathrm{Cl}, 1.077-11.596, P=0.037)$, and a preoperative serum carcinoembryonic antigen level $\geq 5 \mu \mathrm{g} / \mathrm{ml}$ $(\mathrm{OR}=5.466 ; 95 \% \mathrm{Cl}, 1.590-18.787, P=0.007)$.

Conclusions: The aforementioned parameters were the prognostic factors in node-negative ESCC patients, and they associated with a higher probability of recurrence after surgery. These patients should be followed closely, and adjuvant therapy should be considered.
\end{abstract}

Keywords: Esophageal cancer, Prognostic factor, Survival analysis

\section{Background}

Esophageal squamous cell carcinoma (ESCC) is a common malignant tumor occurring in Chinese individuals [1]. At present, esophagectomy plus systematic lymphadenectomy, with or without neoadjuvant chemoradiotherapy is the standard treatment for resectable ESCC [2]. Previous studies have reported several risk factors associated with the prognosis of esophageal cancer after radical resection [3-7]. Among these, lymph node

\footnotetext{
* Correspondence: lingang0608@163.com

Department of Thoracic Surgery, Peking University First Affiliated Hospital,

Peking University, Dahongluo Street 8, Xicheng District, Beijing 100034, China
}

metastasis (LNM) is considered as one of the most important determinants of the prognostic outcome, and the number of positive lymph node is regarded as one of the staging parameters in the American Joint Committee on Cancer (AJCC) Tumor Node Metastasis (TNM) staging classification for esophageal cancer [8]. Platinum-based chemotherapy has been reported to be beneficial in node-positive patients after surgery [9]. However, node-negative patients still have a high risk of recurrence after surgery, and it was reported that up to $40 \%$ of patients without LNM develop recurrent disease after surgery [10]. The prognostic outcome of these 
patients cannot be determined by the number of positive lymph node. Therefore, it is necessary to identify other clinicopathological parameters that could be used as prognostic indicators in these node-negative patients.

In the present study, we evaluated the recurrence rate and analyzed the prognostic factors for recurrence-free survival (RFS) in node-negative patients at a single institution. Our findings are likely to provide a reference point for clinicians to better assess the degree of tumor malignancy and to influence the use of adjuvant treatment in node-negative patients.

\section{Methods}

\section{Patients}

This study was approved by the Ethics Committee of the Peking University First Hospital. We retrospectively reviewed data from 301 patients with esophageal cancer (EC) who underwent esophagectomy for curative intent between January 2011 and June 2017 in the Thoracic Department. The following were excluded: (1) patients with a pathological type of nonsquamous cell carcinoma; (2) patients with pathologically confirmed LNM; (3) patients with tumors that had a positive margin (R1 or R2); (4) patients who received neoadjuvant or adjuvant chemotherapy or chemoradiotherapy; (5) patients who died of non-neoplastic causes; and (6) patients who were lost during follow-up.

\section{Preoperative staging procedures}

Preoperative examinations, which included a thorough physical examination, a thoracic computed tomography (CT) scan, a bone scan, an endoscopic examination and a biopsy, a cervical ultrasound, an abdominal CT scan or an ultrasound, a cardiopulmonary function test, and a hematological profile, were performed to rule out distant metastasis and to evaluate the feasibility of surgery. Positron emission tomography-computed tomography (PET-CT) scans were not routinely performed in our department. They were only used for the preoperative examination of patients with highly suspected metastases, such as lymphadenopathy $(>1 \mathrm{~cm}$ in diameter on a CT scan).

\section{Surgical procedures}

All operations were performed under general anesthesia and double lumen tracheal intubation by qualified surgeons. The surgery consisted of transthoracic esophagectomy and at least two field en-bloc lymphadenectomies (mediastinal and upper abdominal lymph nodes). Cervical lymph node dissections were only reserved for patients with suspected supraclavicular LNM before surgery. Gastric conduit was used for esophageal reconstruction in all patients, except one. The tumor was resected with a negative margin distance $>5 \mathrm{~cm}$. For the resection of the upper ESCC, however, the distance of the proximal margin from the tumor might be $<5 \mathrm{~cm}$, such that the proximal clearance was $>3 \mathrm{~cm}$ at least. There were two surgical approaches: (1) the right-sided transthoracic approach, where esophagectomy and mediastinal lymphadenectomy were performed through the right thoracic cavity. Stomach mobilization and abdominal lymph node dissection were performed at the abdominal stage. An anastomosis was made at the top right thoracic cavity or the left neck. The right-sided approach was used for cases of thoracic ESCC, regardless of the tumor location, except for those tumors located at the esophagogastric junction (EGJ). In the left-sided transthoracic approach, esophagectomy and thoracic and abdominal lymph node dissection were performed through the left thoracic cavity. An esophagogastric anastomosis was made underneath the aortic arch or at the left neck. The left-sided approach was used for cases of middle and lower ESCC and for tumors located at the EGJ. The extent of lymph node (LNs) dissection was as follows. During the left-sided procedure, the LNs at the paraoesophageal region (middle and lower paraoesophageal sites), the mediastinum (subcarinal, tracheobronchial, supradiaphragmatic, and posterior mediastinal sites), and the upper abdominal region (paracardial sites; LNs along the celiac, left gastric, and splenic arteries) were removed. During the right-sided procedure, in addition to the LNs that were dissected in the left-sided approach, the LNs along the bilateral recurrent nerves were also removed. After surgery, the specimens were examined by an experienced pathologist to determine whether LNM was present or absent and whether the surgical margin was free of the tumor (R0 resection). When the distance of the proximal margin from the tumor was less than $1 \mathrm{~cm}$, the pathologist reported the precise distance between the surgical margin and the tumor.

\section{Collected clinicopathologic parameters}

The following clinicopathologic parameters were collected:

(1) General information: age, sex, smoking history, body mass index (BMI), preoperative serum carcinoembryonic antigen (S-CEA) level, and preoperative serum squamous cell carcinoma antigen (S-SCC) level.

(2) Surgery-related information: surgical approach, operation time, blood loss during the surgery, and postoperative complications [11].

(3) Postoperative pathology: tumor size, depth of tumor invasion ( $p$ T stage), total number of dissected lymph nodes (TLN), extent of lymphovascular invasion (VI), extent of perineural invasion (NI), tumor grade (well-differentiated (G1) /moderately 
differentiated (G2)/poorly differentiated (G3)), and TNM stage. The dissected lymph nodes were evaluated by well-trained pathologists. Each patient was assigned a pathological staging, according to the AJCC TNM Classification of Carcinoma of the Esophagus and Esophagogastric Junction (8th Edition) [8].

\section{Follow-up}

Outpatient reviews or telephone follow-ups were conducted every 3-4 months for the first 2 years and every 6 months thereafter. The follow-ups were conducted until October 2018 or recurrence. Examinations included chest CT scans and abdominal and cervical ultrasounds. The collected information included the presence or absence of recurrence, date of recurrence, and site of recurrence. The diagnosis of recurrence was based on reports from radiographic tests. The overall survival (OS) was calculated from the operation to the last follow-up or death. The recurrence-free survival (RFS) was calculated from the date of surgery to the first recurrence. Based on the location of the relapse, recurrence was divided into locoregional recurrence or distant metastasis. Locoregional recurrence was defined as a recurrence restricted to the anastomotic site, the area of the original tumor bed or regional lymph nodes (including the cervical, mediastinum, and upper abdominal LNs). Distant recurrence was defined as any recurrence with features beyond those of a locoregional recurrence.

\section{Statistical analysis}

SPSS 22.0 software (IBM Corporation, USA) was used for statistical analysis. Continuous variables were expressed as the mean \pm standard deviation $(\mathrm{SD})$ or median (range). Categorical variables were expressed as a percentage. All variables, including the demographic data, operative information and tumor characteristics, were analyzed. Kaplan-Meier methods were used to construct the RFS curves. The survival difference of each variable on RFS was analyzed by the log-rank test. The number of patients at risk was calculated for the beginning of each time period. Univariate and multivariate analyses were performed using the Cox proportional hazards regression model. Variables that had a significance level of $P<0.1$ in univariate analysis were included in multivariate Cox regression analysis. All statistical tests were 2 -sided, and a $P$-value $<0.05$ was considered statistically significant.

\section{Results}

\section{General characteristics of patients}

There were 301 patients with EC who were treated with surgery during this period. The following were excluded: (1) patients with a pathological type of nonsquamous cell carcinoma $(n=8)$; (2) patients with pathologically confirmed LNM ( $n=147)$; (3) patients with tumors that had a positive margin (R1 or $\mathrm{R} 2)(\mathrm{n}=1)$; (4) patients who received neoadjuvant or adjuvant chemotherapy or chemoradiotherapy $(n=34)$; (5) patients who died of non-neoplastic diseases $(n=8)$; and (6) patients who were lost during follow-up $(n=2)$. As a result, 101 patients were enrolled in this study.

Of these patients, 78 were male (77.2\%), with a median age of 64 years (range: $47-85$ years). The mean S-CEA and S-SCC levels were $2.6 \pm 1.5 \mu \mathrm{g} / \mathrm{ml}$ (range: 0.6$8.7 \mu \mathrm{g} / \mathrm{L}$ ) and $2.5 \pm 7.0 \mu \mathrm{g} / \mathrm{ml}$ (range: $0.3-70.0 \mu \mathrm{g} / \mathrm{ml}$ ), respectively. The tumor was located in the upper third of the esophagus in 11 patients (10.4\%), the middle segment of the esophagus in 58 patients (56.5\%), and the lower third of the esophagus and the gastroesophageal junction in 32 patients (33.0\%). Surgery was performed using left and right approaches in 44.3 and $55.7 \%$ of patients, respectively. Complications developed in $27.7 \%$ of patients after surgery. The TLN was $23(8-56)$ for the entire study population. The median number of TLNs stratified by surgical approach was $23(9-55)$ for the left-sided approach and 22.5 (8-56) for the right-sided approach, respectively. Among the 101 patients, 9 (8.9\%) underwent cervical LN dissection or sampling, and the median number of removed LNs was 3 (1-9). All patients underwent thoracic and abdominal LN dissection, and the median numbers of removed LNs were 13 (1-41) and 9 (1-25), respectively. VI and NI were present in 5.9 and $14.9 \%$ of patients, respectively. The tumor grade was well differentiated (G1) in 16 patients $(15.8 \%)$, moderately differentiated (G2) in 70 patients (69.3\%), and poorly differentiated (G3) in 15 patients (14.9\%). There were 51 patients $(50.1 \%)$ with stage I disease and 50 patients (49.9\%) with stage II disease. Among the 101 patients, 19 (18.8\%) patients experienced recurrence. Compared with patients without recurrence, the prognosis of patients with recurrence was significantly worse $(P<0.001)$ (Fig. 1$)$. The clinical characteristics of the patients are summarized in Table 1.

\section{Recurrence patterns}

Follow-up was performed until October 2018 or recurrence. The median follow-up time for the 101 patients was 41 months (range: 4-92 months). For the 19 patients who developed recurrence, recurrence (17 patients, 89.5\%) usually occurred within the first three years after surgery. Recurrence peaked within the first year (8 patients, $42.1 \%$ ) and then dropped rapidly after the third year after surgery ( 1 patient per year). The most common pattern of relapse was local recurrence $(n=11,57.9 \%)$, followed by distant recurrence $(n=7,36.8 \%)$; one patient developed local and distant recurrence simultaneously. The details of the recurrences are presented in Table 2. 


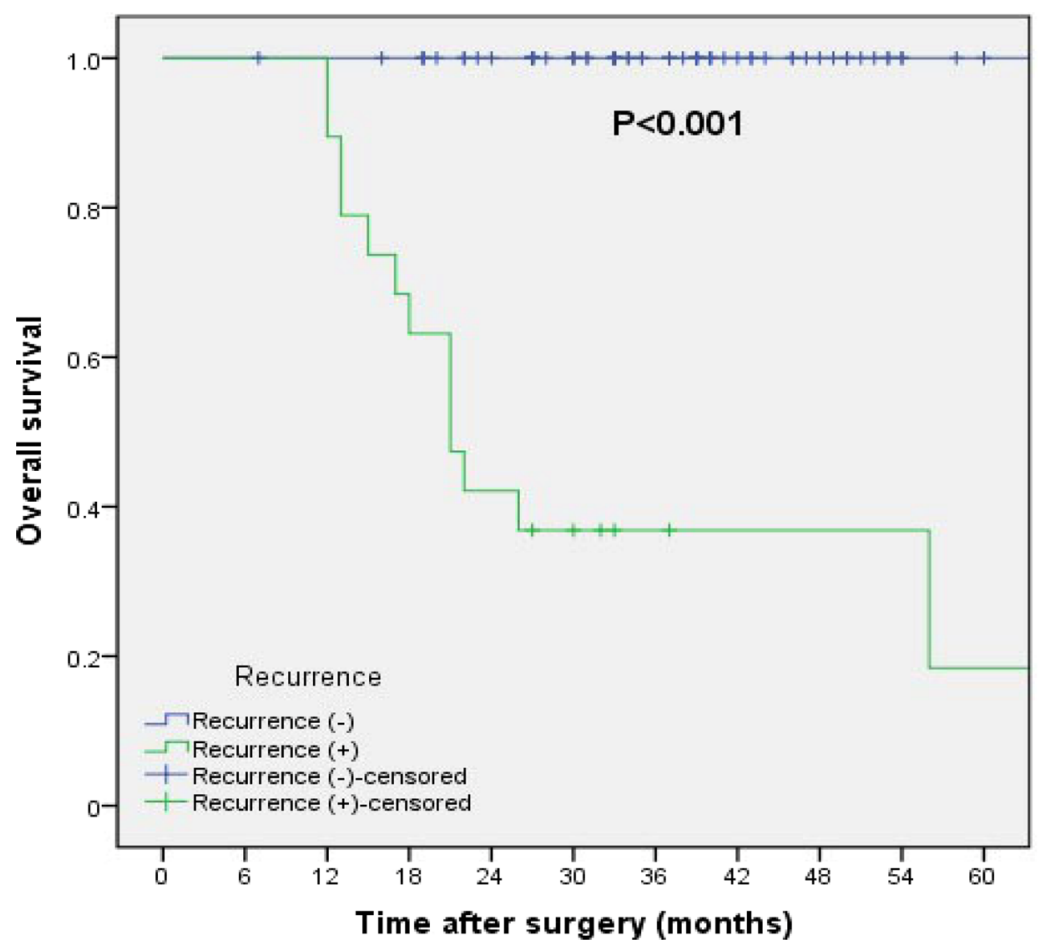

$\begin{array}{llllllllllll}\text { Patients at risk } & & & & & & & & & & & \\ \text { Recurrence (-) } & 82 & 82 & 81 & 80 & 73 & 62 & 46 & 30 & 23 & 15 & 12 \\ \text { Recurrence (+) } & 19 & 19 & 19 & 19 & 8 & 6 & 3 & 2 & 2 & 2 & 1\end{array}$

Fig. 1 Overall survival curves for $p$ NO esophageal cancer patients stratified by recurrence $(n=101)$

Risk factors associated with recurrence in ESCC patients The results of univariate analysis indicated that tumor location $(P=0.011)$, presence of VI $(P<0.001)$, CEA level $(P=0.003)$, and tumor grade $(P=0.011)$ were significantly associated with the RFS of patients. The results of multivariate analysis using the Cox proportional hazards regression model with stepwise selection also demonstrated that the independent prognostic factors for decreased RFS in patients with node-negative disease were a tumor located in the upper chest $(P=0.007$, odds ratio $[\mathrm{OR}]=4.767), \quad \mathrm{CEA} \geq 5 \mu \mathrm{g} / \mathrm{ml} \quad(P=0.007, \quad \mathrm{OR}=$ $5.466)$ and the presence of VI $(P=0.037, \mathrm{OR}=3.534)$. The details are summarized in Tables 3 and 4 .

\section{Impact of different clinicopathological variables on RFS rate} We estimated the 3- and 5- year RFS rates using the Kaplan-Meier method stratified by the aforementioned prognostic factors (Table 5). Poorly differentiated tumors had much worse prognosis than those with well- and moderately differentiated tumors in the log-rank test $(P=0.007)$ (Fig. $2 \mathrm{a})$, although the degree of tumor differentiation was not an independent prognostic factor in multivariate analysis. In regard to the preoperative CEA level, a CEA level $\geq 5 \mu \mathrm{g} / \mathrm{ml}$ was strongly correlated with decreased RFS $(P=0.026)$ (Fig. 2b). Tumors located in the upper segment of the esophagus had a much worse prognosis than those located in the lower and middle chest $(P=0.006)$ (Fig. 3a). The presence of VI was also strongly correlated with the recurrence after surgery $(P=0.001)$ (Fig. 3b).

\section{Discussion}

Recurrence was common for ESCC patients after esophagectomy. Previous studies have reported that the recurrence rate following curative radical resection by open thoracotomy ranged from 42 to $52 \%$ [12, 13]. The risk factors for recurrence included LNM, advanced stage, presence of VI, and location of the tumor [3-7]. Among these factors, LNM was considered the most important risk factor. It was reported that patients with LNM had a much higher recurrence rate than those without LNM [3]. However, even in ESCC patients without lymph node involvement, recurrence developed in several patients. In our study, the recurrence rate was $18.8 \%$ (19/101) in node-negative patients, which was consistent with the rates reported in previous articles $[5,10]$. 
Table 1 Clinicopathological characteristics of node-negative patients $(n=101)$

\begin{tabular}{lllll}
\hline Characteristic & All (\%) & $\begin{array}{l}\text { Recurrence } \\
(+)(\%)\end{array}$ & $\begin{array}{l}\text { Recurrence } \\
(-)(\%)\end{array}$ & $\begin{array}{l}P \text {-value } \\
n=82\end{array}$ \\
\hline
\end{tabular}

Age (year) ${ }^{a}$

$<64$

$\geq 64$

$46(45.5)$

$8(42.1)$

$38(46.3)$

0.738

Gender

Male

$55(54.5)$

$11(57.9)$

$44(53.7)$

Female

$78(77.2)$

$18(94.7)$

60 (73.2)

0.065

Smoking history

Present

50 (49.5)

$1(5.3)$

$22(26.8)$

Absent

$51(50.5)$

$10(52.6)$

$40(51.2)$

0.762

Surgical approach

$\begin{array}{lllll}\text { Left-sided } & 45(44.6) & 7(36.8) & 38(46.3) & 0.453 \\ \text { Right-sided } & 56(55.4) & 12(63.2) & 44(53.7) & \end{array}$

Tumor location

$\begin{array}{lllll}\text { UT } & 11(10.9) & 5(26.3) & 6(7.3) & 0.041^{*} \\ \text { MT } & 58(57.4) & 11(57.9) & 47(57.3) & \\ \text { LT+ EGJ } & 32(31.7) & 3(15.8) & 29(35.4) & \end{array}$

Tumor size $(\mathrm{cm})^{\mathrm{a}}$

$\begin{array}{ccccc}<3 & 47(47.5) & 6(31.6) & 41(51.2) & 0.123 \\ \geq 3 & 52(52.5) & 13(68.4) & 39(48.8) & \\ \text { pT Category } & & & & 0.586\end{array}$

$\begin{array}{llll}0 & 1(1.0) & 0(0.0) & 1(1.2) \\ 1 & 30(29.7) & 4(21.1) & 26(31.7) \\ 2 & 20(19.8) & 4(21.1) & 16(19.5) \\ 3 & 50(49.5) & 11(57.8) & 39(47.6)\end{array}$

p TNM Stage

$\begin{array}{llll}0 & 1(1.0) & 0(0.0) & 1(1.2) \\ I_{1} & 8(7.9) & 2(10.5) & 6(7.3) \\ \mid A_{2} & 22(21.8) & 2(10.5) & 20(24.4) \\ I B & 20(19.8) & 4(21.1) & 16(19.5) \\ \text { IIB } & 50(49.5) & 11(57.8) & 39(47.6)\end{array}$

EGJ gastroesophageal junction, $L T$ lower thoracic, $M T$ middle thoracic, TNM the AJCC Tumor Node Metastasis Classification of Carcinoma of the Esophagus and Esophagogastric Junction (8th Edition); UT upper thoracic

athe median was used as the cutoff value

*:P-value $<0.05$

The present study evaluated the risk factors that influence the development of recurrence in node-negative patients after radical esophagectomy and showed that the presence of VI, a primary tumor located in the upper chest, and a higher S-CEA level were independently associated with decreased RFS after esophagectomy. The presence of VI and NI has been increasingly reported as an adverse prognostic marker in various malignancies [14-16]. A similar phenomenon was also observed by
Table 2 Distribution of recurrence sites

\begin{tabular}{ll}
\hline Recurrence site & No. of patients (\%) \\
\hline Locoregional recurrence & $11(57.9)$ \\
Mediastinal LN & 5 \\
Cervical LN & 4 \\
Anastomotic & 2 \\
Distant recurrence & $7(36.8)$ \\
Bone & 3 \\
Lung & 2 \\
Liver & 1 \\
Heart & 1 \\
Both & $1(5.3)$ \\
Mediastinal LN + liver & 1 \\
Total & 19 \\
\hline
\end{tabular}

LN lymph node

Huang and colleagues in ESCC patients [17]. The presence of VI and NI indicates that tumor cells have infiltrated into the lumina of lymphatic vessels and nerve sheath, which may lead to local spread and distant dissemination $[14,18]$. Similar to these papers, we found that even in patients without LNM, the presence of VI suggested an increased probability of recurrence in ESCC patients after surgery.

In regard to tumor location, previous studies have reported conflicting results. Eloubeidi and colleagues [19] reported that tumors in the lower segment of the esophagus had a better prognosis. However, a large proportion of patients in his study had adenocarcinoma, and the results may not have reflected the exact impact of tumor location on prognosis. In another paper, Doki and colleagues [20] studied 501 patients with EC, most of which had ESCC. The authors reported that these patients had similar 5-year disease-free survival rate, regardless of tumor location. In our study, ESCC tumors located in the upper esophagus had a much worse prognosis than those located in the middle and lower chest, and the 5-year RFS rates were 0.0 and $84.0 \%$, respectively $(P=0.006)$. We put forward two explanations for this: Firstly, almost all tumors could be completely resected, regardless of location, with the strict selection of surgical patients and the improvement of surgical techniques. However, for tumors located in the upper chest, it was more difficult to achieve a wide resection than for those located in the middle and lower chest. Secondly, several studies have reported that patients with ESCC tumors located in the upper esophagus have a higher rate of cervical LNM [21-23]. However, we routinely performed two-field lymph node dissection for thoracic ESSC patients, and cervical lymphadenectomy was reserved only for patients with suspected supraclavicular LNM before surgery for two reasons: (1) Cervical 
Table 3 Univariate analysis of possible prognostic factors in node-negative patients $(n=101)$

\begin{tabular}{|c|c|c|c|}
\hline Possible prognostic factor & OR & $95 \% \mathrm{Cl}$ & $P$-value \\
\hline Age $(<64 \text { yr. vs } \geq 64 \mathrm{yr})^{\mathrm{b}}$ & 0.838 & $0.337-2.086$ & 0.705 \\
\hline$p$-T stage $\left(T_{1}\right.$ vs $\left.T_{2-3}\right)$ & 0.569 & $0.188-1.721$ & 0.318 \\
\hline p-TNM stage (I vs II) & 0.642 & $0.258-1.602$ & 0.342 \\
\hline $\operatorname{TLN}(<23 \text { vs } \geq 23)^{\mathrm{b}}$ & 1.956 & $0.766-4.997$ & 0.161 \\
\hline Sex (male vs female) & 6.193 & $0.826-46.428$ & 0.076 \\
\hline Tumor location (UT vs MT/LT + EGJ) & 3.809 & $1.353-10.719$ & $0.011^{*}$ \\
\hline Lymphovascular invasion (+ vs -) & 7.471 & $2.428-22.990$ & $<0.001^{*}$ \\
\hline Perineural invasion (+ vs -) & 2.365 & $0.848-6.591$ & 0.100 \\
\hline CEA $(\geq 5 \mu \mathrm{g} / \mathrm{ml} \text { vs }<5 \mu \mathrm{g} / \mathrm{ml})^{\mathrm{a}}$ & 5.545 & $1.787-17.203$ & $0.003^{*}$ \\
\hline Tumor grade (poor vs well + moderate) & 3.577 & $1.335-9.581$ & $0.011^{*}$ \\
\hline $\operatorname{SCC}(\geq 1.5 \mu \mathrm{g} / \mathrm{ml} \mathrm{vs}<1.5 \mu \mathrm{g} / \mathrm{ml})^{\mathrm{a}}$ & 0.383 & $0.088-1.659$ & 0.199 \\
\hline Surgical approach (left vs right) & 0.581 & $0.226-1.499$ & 0.262 \\
\hline Smoking history (yes vs no) & 0.935 & $0.375-2.329$ & 0.886 \\
\hline Postoperative complications (yes vs no) & 1.145 & $0.435-3.015$ & 0.784 \\
\hline $\mathrm{BMI}(<23 \text { vs } \geq 23)^{\mathrm{b}}$ & 1.004 & $0.404-2.497$ & 0.993 \\
\hline Operation time $(<445 \mathrm{~min} \text { vs } \geq 445 \mathrm{~min})^{\mathrm{b}}$ & 0.951 & $0.377-2.397$ & 0.915 \\
\hline Blood loss $(<200 \mathrm{ml} v \mathrm{vs} \geq 200 \mathrm{ml})^{b}$ & 0.493 & $0.143-1.699$ & 0.262 \\
\hline Tumor size $(<3.0 \mathrm{~cm} \text { vs } \geq 3.0 \mathrm{~cm})^{\mathrm{b}}$ & 0.445 & $0.169-1.173$ & 0.101 \\
\hline
\end{tabular}

$B M I$ body mass index, $C$ confidence interval, CEA serum carcinoembryonic antigen level, EGJ gastroesophageal junction, $L T$ lower thoracic, $M T$ middle thoracic, OR odds ratio, S-SCC serum squamous cell carcinoma antigen level, TNM the AJCC Tumor Node Metastasis Classification of Carcinoma of the Esophagus and Esophagogastric Junction (8th Edition), TLN total number of removed lymph nodes, UT upper thoracic

${ }^{a}$ the upper limit of the clinical reference value was used as the cutoff value

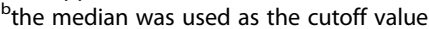

*: P-value $<0.05$

Table 4 Multivariate analysis of independent prognostic factors in patients $(n=101)$

\begin{tabular}{llll}
\hline & OR & $95 \% \mathrm{Cl}$ & $P$-value \\
\hline $\begin{array}{l}\text { Tumor location } \\
\text { UT }\end{array}$ & 4.767 & $1.523-14.916$ & \\
MT/LT+EGJ & 1 & & \\
Lymphovascular invasion & & & $0.007^{*}$ \\
$\quad \begin{array}{l}\text { Present } \\
\text { Absent }\end{array}$ & 3.534 & $1.077-11,596$ & \\
CEA $(\mu \mathrm{g} / \mathrm{ml})^{\text {a }}$ & 1 & & $0.007^{*}$ \\
$\quad \geq 5$ & & & \\
$\quad<5$ & 5.466 & $1.590-18.787$ & \\
Degree of tumor differentiation & 1 & & 0.132 \\
$\quad$ Poor & & & \\
$\quad$ Well/moderate & 2.289 & $0.780-6.717$ & \\
\hline
\end{tabular}

CI confidence interval, CEA serum carcinoembryonic antigen level, $E G J$ gastroesophageal junction, $L T$ lower thoracic, $M T$ middle thoracic, $O R$ odds ratio, UT upper thoracic

${ }^{a}$ the upper limit of the clinical reference value was used as the cutoff value

*: $P$-value $<0.05$
Table 5 Impact of clinicopathological parameters on RFS rates

\begin{tabular}{|c|c|c|c|c|}
\hline Prognostic factor & $\begin{array}{l}\text { No. of } \\
\text { patients }\end{array}$ & $\begin{array}{l}\text { 3-yr RFS } \\
\text { rate (\%) }\end{array}$ & $\begin{array}{l}5 \text {-yr RFS } \\
\text { rate (\%) }\end{array}$ & $P$-value \\
\hline \multicolumn{5}{|l|}{ Tumor location } \\
\hline UT & 11 & 47.1 & 0.0 & \multirow[t]{2}{*}{$0.006^{*}$} \\
\hline$M T / L T+E G J$ & 90 & 86.2 & 84.0 & \\
\hline \multicolumn{5}{|l|}{$\mathrm{Vl}$} \\
\hline Present & 6 & 20.8 & 20.8 & \multirow[t]{2}{*}{$<0.001^{*}$} \\
\hline Absent & 95 & 85.6 & 83.5 & \\
\hline \multicolumn{5}{|l|}{ Tumor grade } \\
\hline Well/moderate & 86 & 86.6 & 84.3 & \multirow[t]{2}{*}{$0.007^{*}$} \\
\hline Poor & 15 & 52.4 & 52.4 & \\
\hline \multicolumn{5}{|l|}{ CEA $(\mu \mathrm{g} / \mathrm{ml})^{\mathrm{a}}$} \\
\hline$<5.0$ & 91 & 84.1 & 82.0 & \multirow[t]{2}{*}{$0.001^{*}$} \\
\hline$\geq 5.0$ & 10 & 42.9 & 42.9 & \\
\hline
\end{tabular}

CEA serum carcinoembryonic antigen level, EGJ gastroesophageal junction, $L T$ lower thoracic, MT middle thoracic, RFS recurrence-free survival,

UT upper thoracic, VI lymphovascularr invasion

${ }^{a}$ the upper limit of the clinical reference value was used as the cutoff value *: P-value $<0.05$ 


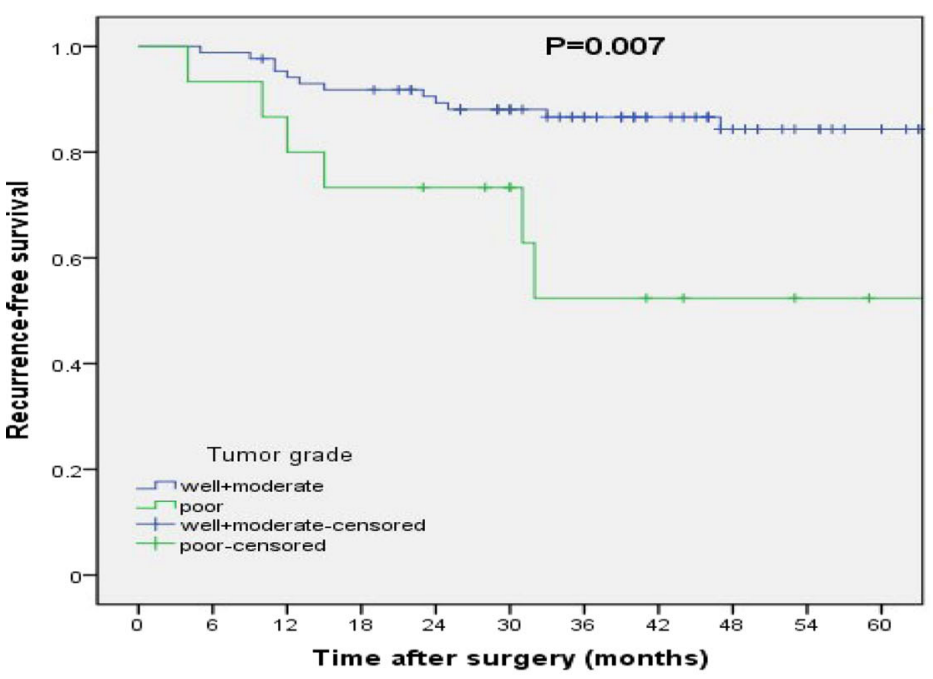

A

Patients at risk

Well/moderate

Poor
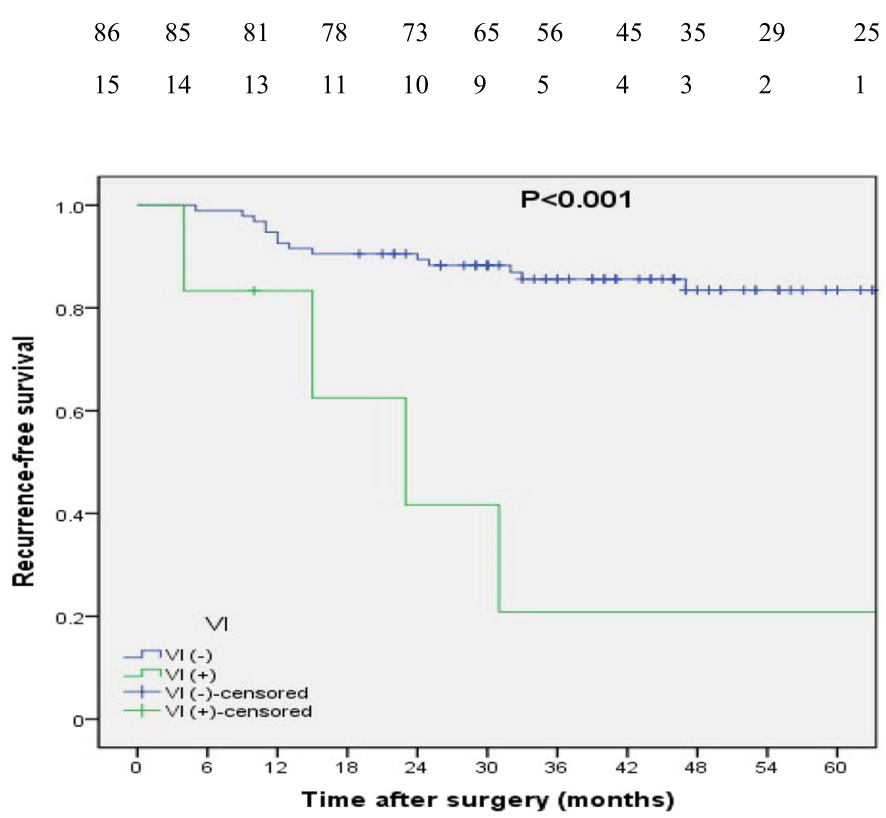

B

Patients at risk

VI (+)

VI (-)

$\begin{array}{lllllllllll}6 & 5 & 4 & 3 & 2 & 2 & 1 & 1 & 1 & 1 & 1 \\ 95 & 94 & 90 & 86 & 81 & 72 & 60 & 48 & 37 & 30 & 25\end{array}$

Fig. 2 Recurrence-free survival curves for $p$ NO patients $(n=101)$ stratified by tumor grade $(\mathbf{a})$ and lymphovascular invasion $(\mathbf{b})$

LN dissection associated with more postoperative complications, such as cord paralysis and aspiration [22, 23], and (2) the prognostic benefits of cervical lymphadenectomy remained inconclusive [22, 23]. The aforementioned reasons could explain the higher postoperative recurrence rate for patients with ESCC tumors located in the upper esophagus.

Tumor markers have been reported to associate with the prognosis of ESCC. Zhang and colleagues [24] studied 107 patients with locally advanced ESCC and found 


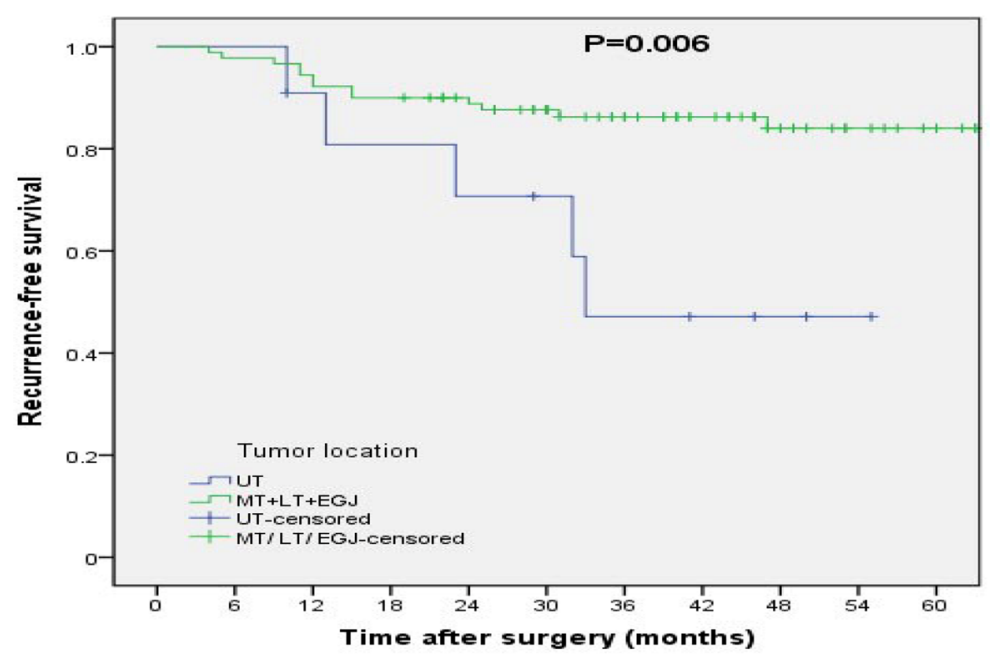

A

\section{Patients at risk}

$\begin{array}{llllllllllll}\text { MT/LT + EGJ } & 90 & 88 & 85 & 81 & 76 & 68 & 57 & 46 & 36 & 30 & 26 \\ \text { UT } & 11 & 11 & 9 & 8 & 7 & 6 & 4 & 3 & 1 & 1 & \end{array}$

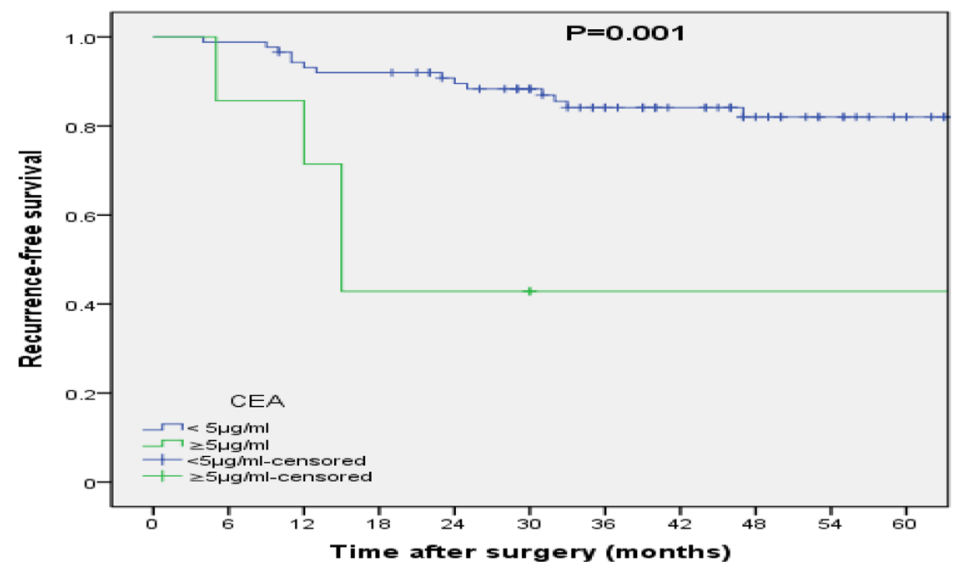

B

\section{Patients at risk}

$\begin{array}{llllllllllll}<\mathbf{5 . 0} \boldsymbol{\mu g} / \mathbf{m l} & 88 & 87 & 82 & 80 & 74 & 67 & 56 & 46 & 37 & 30 & 25 \\ \mathbf{2 5 . 0} \boldsymbol{\mu g} / \mathbf{m l} & 7 & 6 & 6 & 3 & 3 & 3 & 1 & 1 & 1 & 1 & 1\end{array}$

Fig. 3 Recurrence-free survival curves for $p$ No patients $(n=101)$ stratified by tumor location $(\mathbf{a})$ and preoperative serum carcinoembryonic antigen level (b)

that cytokeratin-19 expression and the CEA levels were independent prognostic predictors for ESCC patients treated with concurrent chemoradiotherapy. Similarly, we found that an elevated S-CEA level associated with an increased recurrence rate. Kijima and colleagues [25] reported that stromal CEA expression plays an important role in the invasion of ESCC into the lymphatic system, which might explain the worse prognosis of patients with higher S-CEA levels. However, the S-SCC level was not recognized as an indicator for recurrence in our study.

Although the degree of tumor differentiation was not an independent prognostic factor in multivariate analysis, it was found to be a prognostic factor in the log-rank 
test $(P=0.007)$. The degree of tumor differentiation has been reported to be associated with the prognosis in ESCC patients. Situ and colleagues ${ }^{5}$ studied 317 ESCC patients with stage T2N0M0 and found that tumor grade was an independent prognostic factor $(P=0.011)$. In a study of 292 patients, it was reported that histologic differentiation was an independent prognostic factor for the survival of patients with ESCC $(P<0.001)$ [26]. The results we observed were similar to those described in the aforementioned papers. Several investigators have discovered that poorly differentiated tumors can synthesize additional cancer-promoting factors, which might explain the poor prognosis of patients with poorly differentiated esophageal cancers [27].

This study had several limitations. First, our study was a retrospective study with potential bias. Second, the number of patients included in our study was relatively small. Third, the follow-up time was relatively short, and long-term follow-up information was lacking.

\section{Conclusion}

In conclusion, the presence of VI, a tumor located in the upper chest, and a preoperative S-CEA level $\geq 5 \mu \mathrm{g} / \mathrm{ml}$ were the prognostic factors in node-negative ESCC patients, and they associated with a higher probability of recurrence after surgery. These patients should be followed closely, and adjuvant therapy should be considered.

\section{Abbreviations}

AJCC: American Joint Committee on Cancer; BMI: Body mass index; CEA: Carcinoembryonic antigen; CT: Computed tomography; EC: Esophageal cancer; EGJ: Gastroesophageal junction; ESCC: Esophageal squamous cell carcinoma; LN: Lymph node; LNM: Lymph node metastasis; LT: Lower thoracic; MT: Middle thoracic; NI: Perineural invasion; OR: Odds ratio: OS: Overall survival; RFS: Recurrence-free survival; SCC: Squamous cell carcinoma antigen; SD: Standard deviation; TLN: Total number of dissected lymph nodes; TNM: Tumor node metastasis; UT: Upper thoracic; Vl: Lymphovascular invasion

\section{Acknowledgements}

We acknowledge TopEdit LLC for the linguistic editing and proofreading during the preparation of this manuscript.

\section{Funding}

Not applicable.

\section{Availability of data and materials}

The datasets used during the current study are available from the corresponding author on reasonable request.

\section{Authors' contributions}

LG: designed the study; collected, analyzed and interpreted the data; wrote the report; LHB: collected the data; LJ: participated in discussion and provided useful critique. All authors read and approved the final manuscript.

\section{Ethics approval and consent to participate}

This study was approved by the Ethics Committee of the Peking University First Hospital, and the requirement for informed consent was waived.

\section{Consent for publication}

Not applicable.

\section{Competing interests}

The authors declare that they have no competing interests.

\section{Publisher's Note}

Springer Nature remains neutral with regard to jurisdictional claims in published maps and institutional affiliations.

Received: 2 January 2019 Accepted: 4 March 2019

Published online: 12 March 2019

\section{References}

1. Lin CS, Chang SC, Wei YH, et al. Prognostic variables in thoracic esophageal squamous cell carcinoma. Ann Thorac Surg. 2009;87:1056-65.

2. Lutz MP, Zalcberg JR, Ducreux M, et al. Highlights of the EORTC St. Gallen international expert consensus on the primary therapy of gastric, gastroesophageal and esophageal cancer - differential treatment strategies for subtypes of early gastroesophageal cancer. Eur J Cancer. 2012;48:2941-53.

3. Wang N, Jia Y, Wang J, et al. Prognostic significance of lymph node ratio in esophageal cancer. Tumour Biol. 2015;36:2335-41.

4. Wang S, Chen X, Fan J, Lu L. Prognostic significance of lymphovascular invasion for thoracic esophageal squamous cell carcinoma. Ann Surg Oncol. 2016;23:4101-9.

5. Situ D, Wang J, Lin P, et al. Do tumor location and grade affect survival in pT2NOMO esophageal squamous cell carcinoma? I Thorac Cardiovasc Surg. 2013;146:45-51.

6. Zeybek A, Erdoğan A, Gülkesen KH, et al. Significance of tumor length as prognostic factor for esophageal cancer. Int Surg. 2013;98:234-40.

7. Ren C, Cai XY, Qiu MZ, et al. Impact of body mass index on survival of esophageal squamous carcinoma patients in southern China. J Thorac Dis. 2015;7:337-45.

8. Rice TW, Patil DT, Blackstone EH. $8^{\text {th }}$ edition AJCC/UICC staging of cancers of the esophagus and esophagogastric junction: application to clinical practice. Ann Cardiothorac Surg. 2017;6:119-30.

9. Lee J, Lee KE, Im YH, et al. Adjuvant chemotherapy with 5-fluorouracil and cisplatin in lymph node-positive thoracic esophageal squamous cell carcinoma. Ann Thorac Surg. 2005;80:1170-5.

10. Guo XF, Mao T, Gu ZT, Ji CY, Fang WT, Chen WH. Clinical study on postoperative recurrence in patients with pNO esophageal squamous cell carcinoma. J Cardiothorac Surg. 2014;9:150-4.

11. Booka E, Takeuchi H, Nishi T, et al. The impact of postoperative complications on survivals after esophagectomy for esophageal cancer. Medicine (Baltimore). 2015:94:e1369-78.

12. Nakagawa S, Kanda T, Kosugi S, Ohashi M, Suzuki T, Hatakeyama K. Recurrence pattern of squamous cell carcinoma of the thoracic esophagus after extended radical esophagectomy with three-field lymphadenectomy. J Am Coll Surg. 2004:198:205-11.

13. Miyata H, Yamasaki M, Kurokawa Y, et al. Survival factors in patients with recurrence after curative resection of esophageal squamous cell carcinomas. Ann Surg Oncol. 2011;18:3353-61.

14. Liebig C, Ayala G, Wilks JA, Berger DH, Albo D. Perineural invasion in cancer: a review of the literature. Cancer. 2010;115:3379-91.

15. Chatterjee $D$, Katz MH, Rashid A, et al. Perineural and intra-neural invasion in posttherapy pancreaticoduodenectomy specimens predicts poor prognosis in patients with pancreatic ductal adenocarcinoma. Am J Surg Pathol. 2012;36:409-17.

16. Cornwell LB, McMasters KM, Chagpar AB. The impact of lymphovascular invasion on lymph node status in patients with breast cancer. Am Surg. 2011;77:874-7.

17. Huang Q, Luo K, Chen C, et al. Identification and validation of lymphovascular invasion as a prognostic and staging factor in nodenegative esophageal squamous cell carcinoma. J Thorac Oncol. 2016;11:583-92.

18. D'Annoville T, D'Journo $X B$, Loundou $A$, et al. Prognostic impact of the extracapsular lymph node involvement on disease-free survival according to the 7th edition of American joint committee on cancer staging system. Eur I Cardiothorac Surg. 2013:44:e207-11.

19. Eloubeidi MA, Desmond R, Arguedas MR, Reed CE, Wilcox CM. Prognostic factors for the survival of patients with esophageal carcinoma in the US: the importance of tumor length and lymph node status. Cancer. 2010;95:1434-43. 
20. Doki Y, Ishikawa O, Takachi K, et al. Association of the primary tumor location with the site of tumor recurrence after curative resection of thoracic esophageal carcinoma. World J Surg. 2005;29:700-7.

21. Chen J, Cai W, Zheng X, et al. The pattern of cervical lymph node metastasis in thoracic esophageal squamous cell carcinoma may affect the target decision for definitive radiotherapy. Radiother Oncol. 2017;123:382-6.

22. Shim YM, Kim HK, Kim K. Comparison of survival and recurrence pattern between two-field and three-field lymph node dissections for upper thoracic esophageal squamous cell carcinoma. J Thorac Oncol. 2010;5:707-12.

23. Nozoe T, Kakeji Y, Baba H, Maehara Y. Two-field lymph-node dissection may be enough to treat patients with submucosal squamous cell carcinoma of the thoracic esophagus. Dis Esophagus. 2010;18:226-9.

24. Zhang $\mathrm{HQ}$, Wang RB, Yan HJ, et al. Prognostic significance of CYFRA21-1, CEA and hemoglobin in patients with esophageal squamous cancer undergoing concurrent chemoradiotherapy. Asian Pac J Cancer Prev. 2012;13:199-203

25. Kijima H, Oshiba G, Kenmochi T, et al. Stromal CEA immunoreactivity is correlated with lymphatic invasion of human esophageal carcinoma. Int J Oncol. 2000;16:677-82.

26. Li H, Zhang Q, Xu L, Chen Y, Wei Y, Zhou G. Factors predictive of prognosis after esophagectomy for squamous cell cancer. J Thorac Cardiovasc Surg. 2009:137:55-9

27. Huang C, Yu Z, Yang H, Lin Y. Increased MALAT1 expression predicts poor prognosis in esophageal cancer patients. Biomed Pharmacother. 2016;83:8-13.

Ready to submit your research? Choose BMC and benefit from:

- fast, convenient online submission

- thorough peer review by experienced researchers in your field

- rapid publication on acceptance

- support for research data, including large and complex data types

- gold Open Access which fosters wider collaboration and increased citations

- maximum visibility for your research: over $100 \mathrm{M}$ website views per year

At BMC, research is always in progress.

Learn more biomedcentral.com/submissions 